\title{
Effect of Whisker Orientation on Monotonic and Fatigue Strength of Aluminium Cast Alloy Locally Reinforced by SiC Particles and $\mathrm{Al}_{2} \mathrm{O}_{3}$ Whiskers Under Monotonic and Cyclic load*
}

\author{
Rafiquzzaman MD. ** and Yoshio ARAI*** \\ ${ }^{* *}$ Graduate Student of Saitama University \\ ${ }^{* * *}$ Graduate School of Science and Engineering, Saitama University \\ 255 Shimo-Ohkubo, Sakura-ku, Saitama 338-8570, Japan \\ Email: yarai@mech.saitama-u.ac.jp
}

\begin{abstract}
In this study, the effect of whisker orientation on monotonic and fatigue strength of aluminium cast alloy locally reinforced by $\mathrm{SiC}$ particles and $\mathrm{Al}_{2} \mathrm{O}_{3}$ whiskers are investigated. The material is monotonically and cyclically deformed to failure at room temperature. A significant effect of reinforcement orientation on the monotonic strength and fatigue strength are observed experimentally and numerically. With respect to the stress direction the whisker orientation gives significant difference in strength of this material. SEM analysis shows almost all whiskers are transversely debonded when whisker direction is perpendicular to the stress direction and almost all whiskers are broken when the whisker direction is parallel to the stress direction. A three-dimensional single whisker unit cell model of cylindrical shape whisker in the periodic boundary condition is conducted using finite element method (FEM) to describe the overall behavior of the composite. The prediction results based on FEM analysis is found to be in reasonable agreement with the experimental observations.
\end{abstract}

Key words: Metal Matrix Composites (MMCs), Whisker Orientation, Fracture, Fatigue, Strength

\section{Introduction}

The application of metal matrix composites (MMCs) to automotive industry especially in brake component (disc brake ) has been receiving an attention because of their high strength and stiffness, light weight or low density, high temperature properties and excellent wear resistance compared to the unreinforced materials ${ }^{(1)}$. Some of the fabrication techniques of the composite materials squeeze casting have now become one of the most feasible techniques for the production of low cost $\mathrm{MMCs}^{(2)}$. Local reinforcement of materials produces lighter components and improves the performance in the area required under service conditions. For example, in the brake disc application, ductile aluminium alloy which has high fracture toughness supports the whole disc and the reinforced part by ceramic particles/whiskers is used in the area required (e.g. frictional area) ${ }^{(2)}$. Due to thermal load and external load such as brake force acting on the component, the locally reinforced materials are subjected to in-plane load of the reinforced face in which the whiskers are distributed randomly and also out-of-plane load which is perpendicular to the whisker orientation. Because of the improved mechanical properties, many researchers have investigated the monotonic and cyclic fracture behavior and the fracture mechanisms of ceramic whisker/ particle based $\mathrm{MMCs}^{(3)-(8)}$. The mechanical properties of whisker/ particle

*Received 24 Aug., 2007 (No. 07-0401) [DOI: 10.1299/jmmp.2.47] 
composites are strongly dependent on their compositions and the volume fraction as well as the arrangement of reinforcement such as random orientation and distributions. In the whisker/fiber composites, the whisker/fiber orientation with respect to the load is very important. Some studies have shown that the composite strength highly depends on its reinforcement orientation ${ }^{(9)-(14)}$. Kang et al. showed that the elastic modulus and fiber axial stress is strongly dependent on the fiber orientation angle $(\alpha)^{(9)(10)}$. The strength of whisker/particle composites is greatly influenced by load transfer from matrix to reinforcement ${ }^{(10)}$. The load transfer between whisker and matrix in a metal matrix composite (MMC) depends on the properties and conditions of the whisker/matrix interfacial region. The interfacial bond has a remarkable effect on stress transfer from matrix to the whisker. Good interfacial bonding enhances the stress transfer between matrix and fiber which results in increase overall strength ${ }^{(10)}$. Elastic modulus and axial stress of composites is increased with decreasing the orientation angle ( $\alpha=0^{\circ}$ is parallel to the stress direction). Other literature showed that the stress in whisker parallel to the loading direction $\left(\alpha=0^{\circ}\right)$ is largest compared with other orientation angle ${ }^{(12)}$. Trojanova et al. ${ }^{(13)}$ demonstrated that the tensile strength is significantly increased in the parallel orientation ( $\alpha=0^{\circ}$ ) of whisker composite compared with the perpendicular orientation $\left(\alpha=90^{\circ}\right.$ ) of $\mathrm{Al}_{2} \mathrm{O}_{3}$ whisker MMC. The effect of whisker orientation on the strength of hybrid composites (reinforced by whisker and particle) is very complicated due to the presence of whiskers and particles. Due to the complicated microstructure, various experimental and numerical investigations are needed to be explained to clarify the fracture mechanism of the composite ${ }^{(14)(15)}$. Thus, in the present work the effect of the whisker orientation on the monotonic strength and fatigue strength and its effect on fracture mechanism of aluminium cast alloy locally reinforced by $\mathrm{SiC}$ particles and $\mathrm{Al}_{2} \mathrm{O}_{3}$ whiskers under monotonic and cyclic load are investigated. Fractographic analysis is used to explain the orientation dependency in fracture mechanism. A three-dimensional single whisker unit cell model of cylindrical shape whisker in the periodic boundary condition is conducted using finite element method (FEM) to describe the overall behavior of the composite.

\section{Materials and experimental procedures}

The specimens used in our study were cut out from a locally reinforced aluminium disc shown in Fig.1. The bend specimen size (width, depth and length) is limited by the limited reinforced part layer thickness. The locally reinforced part were fabricated with squeeze casting method of $100 \mathrm{MPa}$ maximum pressure using hybrid preforms which is made of the $\mathrm{SiC}$ particles (21 volume\%) and $\mathrm{Al}_{2} \mathrm{O}_{3}$ whiskers ( 9 volume\%) and an aluminium alloy of JIS-AC4CH as matrix ${ }^{(16)}$. The squeeze casting pressure of $100 \mathrm{MPa}$ is adequate to overcome the resistance against flow and to press the melt into all the open pores of the hybrid preforms. Volume fraction and mechanical properties are listed in Table 1. The chemical compositions of $\mathrm{AC} 4 \mathrm{CH}$ alloy are listed in Table 2. Two types of specimens were prepared for the bending test. The longitudinal orientation is normal to or parallel to the boundary ( $r-\theta$ plane in Fig. 1) between reinforced part and unreinforced part. The former is called as "locally reinforced material". The latter is called as "homogeneous MMC". The typical microstructure is shown in Fig. 2, which representing the $\mathrm{SiC}$ particles and $\mathrm{Al}_{2} \mathrm{O}_{3}$ whiskers distribution and whisker orientation angle of the composite. Generally, the $\mathrm{Al}_{2} \mathrm{O}_{3}$ whisker orientation in the disc is random in $r-\theta$ plane. In the "homogeneous MMC" specimen whiskers are oriented randomly $\left(\alpha=0^{\circ} \sim 90^{\circ}\right)$ to the load direction (Fig. 2(b)) and in the "locally reinforced material" almost all whiskers are perpendicular $\left(\alpha=90^{\circ}\right)$ to the load direction as shown in Fig. 2 (a) and the cross-section shape is almost circle. Most of the $\mathrm{SiC}$ particles are rectangular shaped with sharp corners and most of the $\mathrm{Al}_{2} \mathrm{O}_{3}$ whiskers are roller shaped shown in Fig.2. The $\mathrm{SiC}$ particles have an average length of $23 \mu \mathrm{m}$ and aspect ratio is nearly 1 . The $\mathrm{Al}_{2} \mathrm{O}_{3}$ whisker length varies over a large range (average length $33 \mu \mathrm{m}$ ) and 
the diameter is nearly the same $(2 \mu \mathrm{m})$ and can be considered as constant. In Al alloy side the $\mathrm{Al}$ has an average grain size of $48 \mu \mathrm{m}$. Bending tests were carried out using special bending fixtures equipped with a $980 \mathrm{~N}$ load cell.

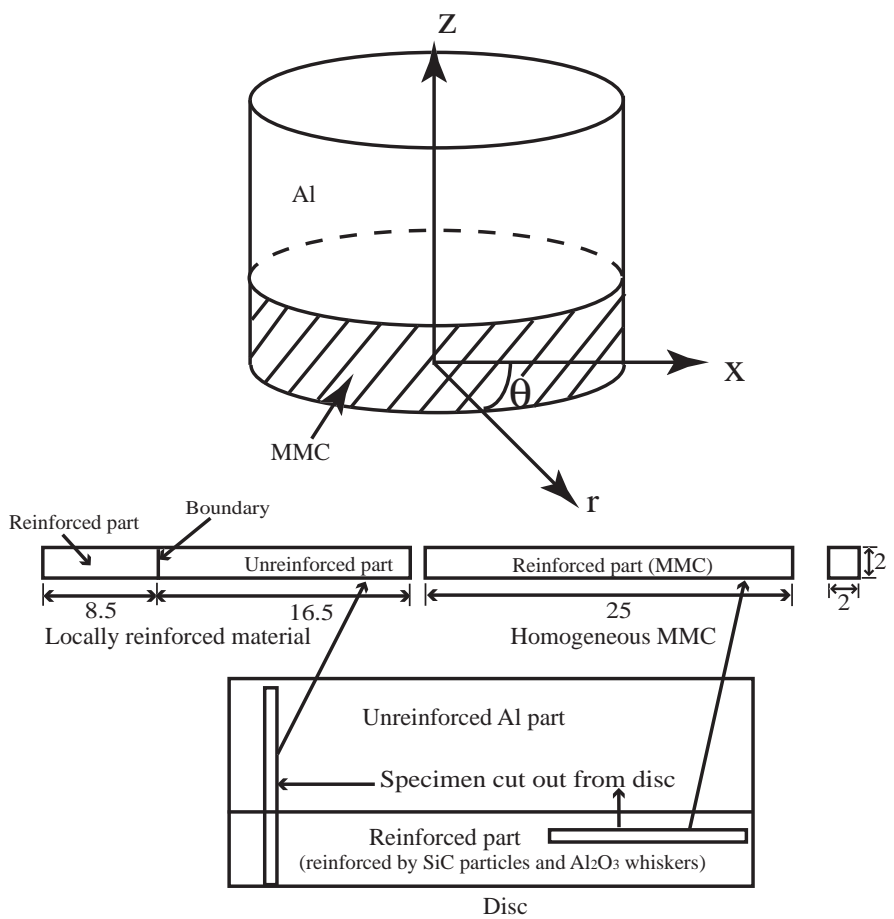

Fig.1 Specimen cut out from a disc (unit: $\mathrm{mm}$ ).

Table 1: Volume fraction and mechanical properties

\begin{tabular}{|c|c|c|c|c|}
\hline Parameters & $\mathrm{Al}_{2} \mathrm{O}_{3}$ & $\mathrm{SiC}$ & AC4CH alloy & MMC \\
\hline Volume contents (\%) & 9 & 21 & 70 & - \\
\hline Young's Modulus (GPa) & 380 & 450 & 70.0 & 142 \\
\hline Poisson's ratio & 0.27 & 0.20 & 0.33 & 0.28 \\
\hline Yield strength $(\mathrm{MPa})$ & - & - & 131 & 166 \\
\hline
\end{tabular}

Table 2: Chemical compositions of AC4CH alloy (wt. \%)

\begin{tabular}{|c|c|c|c|c|}
\hline $\mathrm{Si}$ & $\mathrm{Fe}$ & $\mathrm{Mg}$ & $\mathrm{Ti}$ & $\mathrm{Al}$ \\
\hline 7.99 & $0.2 \max$ & 0.57 & 0.07 & Bal. \\
\hline
\end{tabular}

The inner span was $10 \mathrm{~mm}$ and outer span was $20 \mathrm{~mm}$. Monotonic bending test were conducted with a displacement rate of $0.0025 \mathrm{~mm} / \mathrm{s}$. Strength was calculated from the maximum load at failure as a nominal bend stress. Cyclic fatigue tests were conducted in the load control mode under the load ratio $\mathrm{R}=0.1$ at a frequency of 1 to $10 \mathrm{~Hz}$. The tests were carried out at room temperature. The number of cycles to failure is taken as the fatigue life $\left(\mathrm{N}_{\mathrm{f}}\right)$. Fracture surfaces were comprehensively examined in a scanning electron microscope (SEM) so as to determine the microscopic fracture mode and to characterize the microscopic mechanisms governing fracture. 


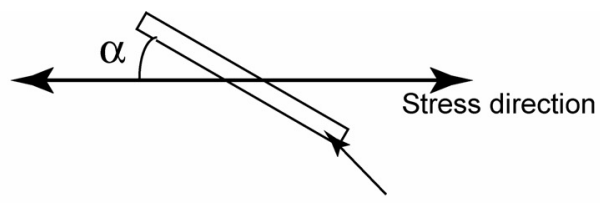

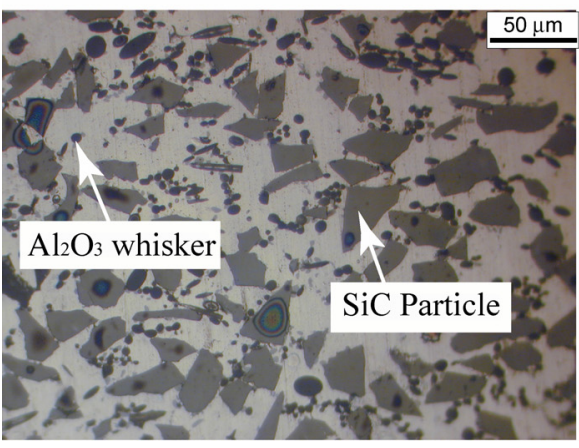

(a)

\section{$\mathrm{Al}_{2} \mathrm{O}_{3}$ whisker}

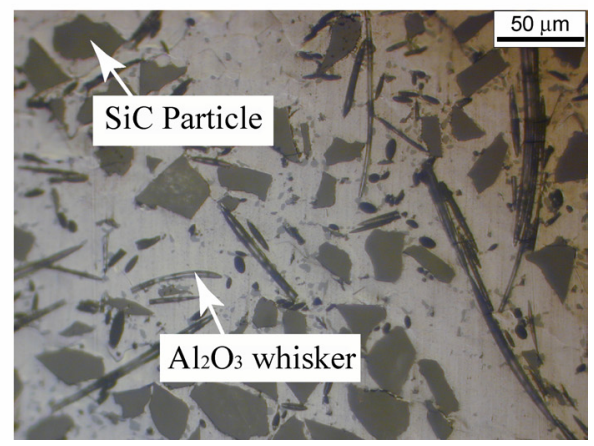

(b)

Fig. 2 Optical micrograph of the composite on the tensile side face, representing the $\mathrm{SiC}$ particle and $\mathrm{Al}_{2} \mathrm{O}_{3}$ whisker distribution and $\mathrm{Al}_{2} \mathrm{O}_{3}$ whisker orientation angle $\alpha$ : (a) locally reinforced material $\left(\alpha=90^{\circ}\right)$ and (b) Homogeneous MMC $\left(\alpha=0^{\circ} \sim 90^{\circ}\right)$.

The microscopic mechanism refers to the local failure processes (fracture of particle or whisker, particle/matrix or whisker/matrix interfacial debonding, dimple fracture of matrix alloy). Electron Beam Induced X-ray analysis (EDX) was used to identify constituents on the fracture surface. Moreover the measured area of dimple, interface debonding and particle/whisker fracture on the fracture surface have also been examined. To determine the area fraction of particle/whisker fracture and interfacial debonding, we have selected the particular area $2 \mathrm{~mm}$ width and $0.05 \mathrm{~mm}$ height from the tensile surface. Therefore, the fractions of the particle and whisker fracture area are defined by the all particle and whisker fracture area divided by the total area measured. The area fractions of particle/matrix or whisker/matrix interface debonding were also measured by the same procedure.

\section{Experimental results and discussions}

\subsection{Monotonic and fatigue test}

The nominal bending stress and displacement curves measured by the four-point bending test for homogeneous MMC and locally reinforced materials are shown in Fig.3. Locally reinforced and homogeneous samples exhibit a significant difference in strength. The average value of fracture stress of locally reinforced material $\left(\alpha=90^{\circ}\right)$ was $305 \mathrm{MPa}$ are less than the scatter band of the value for homogeneous $\operatorname{MMC}\left(\alpha=0^{\circ} \sim 90^{\circ}\right)$ which was $364 \mathrm{MPa}$. The whisker orientation in the MMC may be the cause of low bending strength of the locally reinforced material $\left(\alpha=90^{\circ}\right)$. Whiskers oriented parallel $\left(\alpha=90^{\circ}\right)$ to the bending stress direction give higher monotonic strength of homogeneous $\operatorname{MMC}\left(\alpha=0^{\circ} \sim 90^{\circ}\right)$. The experimental results of fatigue life behavior of homogeneous MMC and locally reinforced material are shown in Fig.4. The horizontal arrows indicate the tests that were suspended after $10^{7}$ cycles. From this figure it can be seen that the fatigue strength of locally reinforced material $\left(\alpha=90^{\circ}\right)$ is lower than the fatigue strength of homogeneous $\operatorname{MMC}\left(\alpha=0^{\circ} \sim 90^{\circ}\right)$. The whisker orientation in the MMC may be the cause of low fatigue strength of locally reinforced material $\left(\alpha=90^{\circ}\right)$. Whiskers randomly oriented relative to the bending stress direction cause longer fatigue life of homogeneous $\operatorname{MMC}\left(\alpha=0^{\circ} \sim 90^{\circ}\right)$. Minimum distance from the fracture location to macroscopic boundary between reinforced part and unreinforced part under monotonic and cyclic load of 
locally reinforced material $\left(\alpha=90^{\circ}\right)$ are shown in Table 3 and Table 4 . As indicated in Table 4, when the maximum stress is low and the matrix alloy is deformed elastically in the reinforced part, (see the results of CTP4-7 in Table 4) the minimum distance of fracture location is far $(0.28 \pm 0.06)$ from the boundary between the reinforced and unreinforced parts.

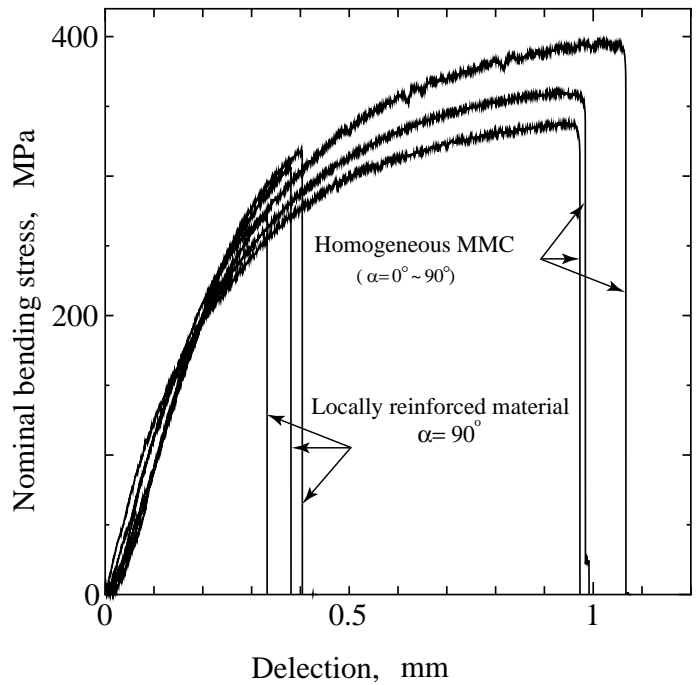

Fig.3 Nominal bending stress versus deflection curves under monotonic loading.

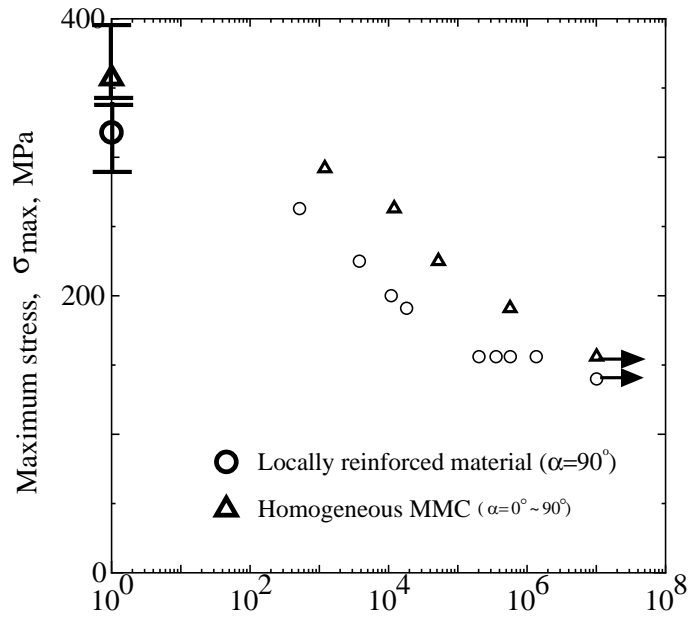

No. of cycle to failure, $\mathrm{N}_{\mathrm{f}}$, cycle

Fig.4 Stress versus fatigue life behavior (stress ratio, $R=0.1$ ). The plots on $\mathrm{N}_{\mathrm{f}}=0$ show average strength under monotonic load.

\subsection{Observation of fracture surfaces}

To clarify the fracture mechanism, fracture surfaces were examined in SEM and the characteristics of the fracture surface were described as follows: The characteristic fracture surface of locally reinforced material $\left(\alpha=90^{\circ}\right)$ is shown in Fig. 5(a). There were many transversely debonding whiskers parallel to the fracture surface. The broken whiskers in the fracture surface were scarce. The whiskers pulled-out could not be seen in the fracture surface. As listed in Table 5, large area fractions of interfacial debonding of $\mathrm{Al}_{2} \mathrm{O}_{3}$ whisker/matrix are observed in locally reinforced materials and the area fractions of $\mathrm{Al}_{2} \mathrm{O}_{3}$ whisker fracture are negligible. From this observation it is pointed out that when whisker direction is perpendicular $\left(\alpha=90^{\circ}\right)$ to the stress direction, almost all whiskers are transversely debonded, that means the lower strength and shorter fatigue life of locally 
reinforced material $\left(\alpha=90^{\circ}\right)$ is corresponding to the interface debonding between whisker-matrix interfaces.

Table 3: Fracture stresses and minimum distance from the fracture location to macroscopic boundary between reinforced part and unreinforced part under monotonic loading of locally reinforced material (all specimens are broken at reinforced part)

\begin{tabular}{|c|c|l|}
\hline Specimen & Fracture stress $(\mathrm{MPa})$ & \multicolumn{1}{|c|}{$\mathrm{d}_{\mathrm{f}}$} \\
\hline $\mathrm{TP} 1$ & 318 & 2 particles $(46 \mu \mathrm{m})$ \\
\hline $\mathrm{TP} 2$ & 306 & 1particles $(23 \mu \mathrm{m})$ \\
\hline $\mathrm{TP} 3$ & 272 & 1particles $(23 \mu \mathrm{m})$ \\
\hline $\mathrm{TP} 4$ & 325 & 1particles $(23 \mu \mathrm{m})$ \\
\hline \multicolumn{2}{|c|}{$\mathrm{d}_{\mathrm{f}}$ minimum distance from boundary to fracture site. }
\end{tabular}

Table 4 Fatigue life and distance from fatigue fracture location to macroscopic boundary of locally reinforced material (all specimens are broken at reinforced part)

\begin{tabular}{|c|c|c|c|}
\hline Specimen & $\sigma_{\max }(\mathrm{MPa})$ & $\mathrm{N}_{\mathrm{f}}$ & $\mathrm{d}_{\mathrm{f}}$ \\
\hline CTP1 & 261 & 517 & 2 particles $(46 \mu \mathrm{m})$ \\
\hline CTP2 & 225 & 3781 & $0.11 \mathrm{~mm}$ \\
\hline CTP3 & 200 & $1.08 \times 10^{4}$ & $0.13 \mathrm{~mm}$ \\
\hline CTP4 & 191 & $1.8 \times 10^{4}$ & $0.34 \mathrm{~mm}$ \\
\hline CTP5 & 156 & $5.73 \times 10^{5}$ & $0.23 \mathrm{~mm}$ \\
\hline CTP6 & 156 & $3.56 \times 10^{5}$ & $0.26 \mathrm{~mm}$ \\
\hline CTP7 & 156 & $2.02 \times 10^{5}$ & $0.31 \mathrm{~mm}$ \\
\hline \multicolumn{3}{|c|}{$\mathrm{d}_{\mathrm{f}}$ minimum distance from the boundary to fracture site, } \\
& $\sigma_{\max }$ maximum stress, $\mathrm{N}_{\mathrm{f}}$ number of cycle to failure.
\end{tabular}

The characteristic fracture surface of homogeneous MMC $\left(\alpha=0^{\circ} \sim 90^{\circ}\right)$ is shown in Fig. 5(b). There were many dimples and broken whiskers in the fracture surface. The transversely debonding whiskers parallel to the fracture surface are scarce. The whiskers

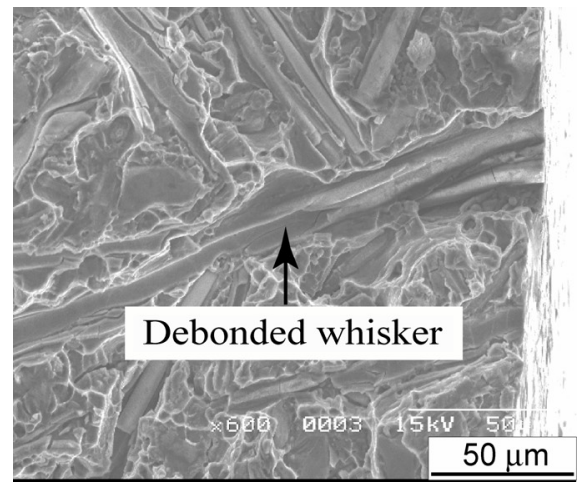

(a) Locally reinforced material $\left(\alpha=90^{\circ}\right)$

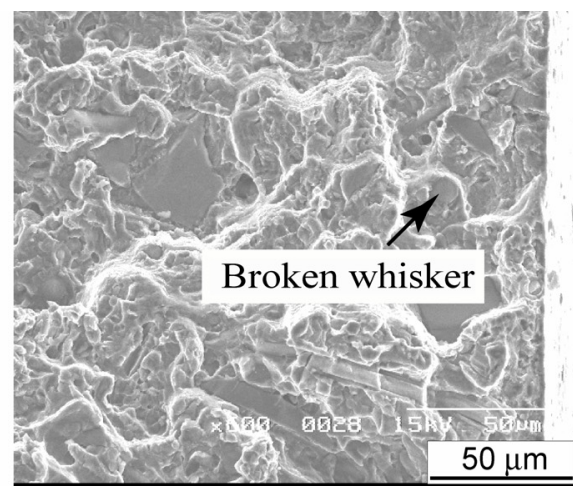

(b) Homogeneous $\operatorname{MMC}\left(\alpha=0^{\circ} \sim 90^{\circ}\right)$

Fig.5 Comparison of two types of fracture surface (a) locally reinforced material $\left(\alpha=90^{\circ}\right)$ (b) Homogeneous $\operatorname{MMC}\left(\alpha=0^{\circ} \sim 90^{\circ}\right)$, under cyclic loading condition (Observed locations are near the tensile side)

pulled-out could not be seen in the fracture surface. As listed in Table 5, large area fractions of $\mathrm{Al}_{2} \mathrm{O}_{3}$ whisker fracture are observed and the area fractions of interfacial debonding of $\mathrm{Al}_{2} \mathrm{O}_{3}$ whisker/matrix are negligible. This means whisker-matrix interface is strong enough 
to avoid whisker pull out in this whisker orientation. Load is transferred from matrix to the whisker and whisker fractures dominate the fracture mechanism. This is one of the reasons why the monotonic strength and fatigue strength of homogeneous MMC is higher than that of locally reinforced material. As indicated in Table 5 the area fractions of $\mathrm{SiC}$ particle fracture and the interfacial debonding of $\mathrm{SiC}$ particle/matrix are almost the same for the both materials.

Table 5: Area fractions of SiC particle and $\mathrm{Al}_{2} \mathrm{O}_{3}$ whisker fracture and interface debonding between $\mathrm{SiC}$ particle-matrix and $\mathrm{Al}_{2} \mathrm{O}_{3}$ whisker-matrix under cyclic loading conditions

\begin{tabular}{|c|c|c|c|c|c|}
\hline \multirow{2}{*}{ Material } & \multicolumn{2}{|c|}{$\mathrm{SiC}$ particle } & \multicolumn{2}{|c|}{$\mathrm{Al}_{2} \mathrm{O}_{3}$ whisker } & \multirow{2}{*}{$\begin{array}{c}\mathrm{Al}(\text { matrix }) \\
\text { area }(\%)\end{array}$} \\
\hline & $\mathrm{F}^{\mathrm{a}}(\%$ & $\mathrm{D}^{\mathrm{b}}(\%)$ & $\mathrm{F}^{\mathrm{a}}(\%$ & $\mathrm{D}^{\mathrm{b}}(\%)$ & \\
\hline $\begin{array}{c}\text { Homogeneous } \\
\operatorname{MMC}\left(\alpha=0^{\circ} \sim 90^{\circ}\right)\end{array}$ & 1.9 & 20.6 & 11 & 0.1 & 69.0 \\
\hline $\begin{array}{l}\text { Locally reinforced } \\
\text { material }\left(\alpha=90^{\circ}\right)\end{array}$ & 1.2 & 19.6 & 0.6 & 9.1 & 68.4 \\
\hline
\end{tabular}

${ }^{\mathrm{a}} \mathrm{F}$ fracture area, ${ }^{\mathrm{b}} \mathrm{D}$ debonding area

\subsection{Observation of fracture initiation site}

In order to characterize the fracture initiation, fracture surfaces were examined in SEM and EDX and the characteristics of the fracture initiation were described as follows: The cyclic fracture surface of homogeneous MMC $\left(\alpha=0^{\circ} \sim 90^{\circ}\right)$ around the fatigue crack initiation site is shown in Fig.6. In Fig.6, the areas indicated by $\mathrm{W}$ were areas that contained a lot of $\mathrm{Al}(99 \%)$ and a small amount of $\mathrm{Si}(1 \%)$ according to EDX analysis.
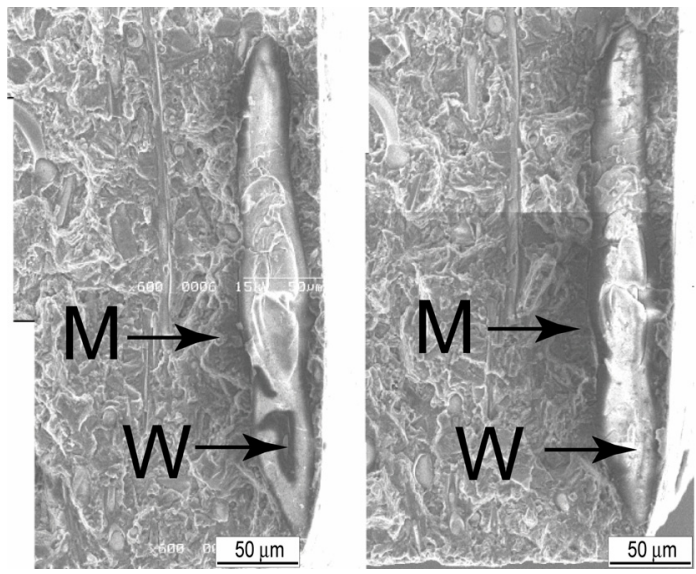

Fig.6 Matching fatigue fracture surface of homogeneous MMC $\left(\alpha=0^{\circ} \sim 90^{\circ}\right)$ after fatigue fracture $\sigma_{\max }=191 \mathrm{MPa}, N_{f}=67617$.

Therefore, a W-W pair in the matching halves can be assigned to a $\mathrm{Al}_{2} \mathrm{O}_{3}$ whisker fracture. The composition of the area indicated by $\mathrm{M}$ in Fig. 6 contains a lot of $\mathrm{Al}(92 \%)$ and a small amount of $\mathrm{Si}(8 \%)$. Therefore, the fatigue crack initiates from a coarse $\mathrm{Al}_{2} \mathrm{O}_{3}$ whisker fracture and propagates through the aluminium alloy matrix. The cyclic fracture surface of locally reinforced material $\left(\alpha=90^{\circ}\right)$ around the fatigue crack initiation site is shown in Fig.7. The fatigue crack initiation process is independent on the whisker orientation such that a coarse $\mathrm{Al}_{2} \mathrm{O}_{3}$ whisker fracture is the origin and the crack propagates through the aluminium alloy matrix. 


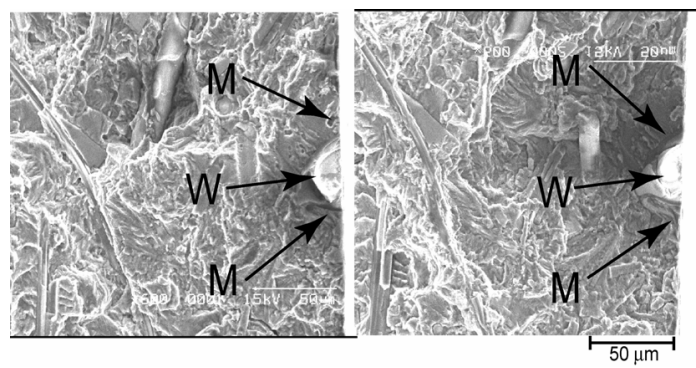

Fig.7 Matching fracture surface of locally reinforced material $\left(\alpha=90^{\circ}\right)$ after fatigue fracture, maximum stress $\sigma_{\max }=156 \mathrm{MPa}, N_{f}=5.73 \times 10^{5}$.

\section{Numerical model}

In this numerical analysis, a three-dimensional single whisker unit cell model of cylindrical shape whisker in the periodic boundary condition is conducted using finite element method (FEM) to describe the overall behavior of the composite. A schematic illustration and finite-element mesh of the model is shown in Fig. 8. In this model the whisker is embedded in a matrix in three-dimensional packing arrangement. For this model, we assume that the whisker was perfect cylinder of length $l$ and diameter d. Size determination of the model was made by following formulae: $\pi l d^{2} / 4 L H^{2}=V_{w}$ where $V_{w}$ is whisker volume fraction, $L$ is longitudinal whisker spacing and $H$ is the transverse whisker spacing. Whisker volume fraction is modeled as real microstructure of 30 vol. \% reinforcement in an $\mathrm{Al}$ alloy matrix. The whisker orientation is represented by the angle $\alpha$ between whisker's long axis and loading direction. To avoid complicated morphology we assumed all reinforcement to be whisker. This assumption may give overestimation of effect of whisker orientation on the stress distribution. Because of the symmetry of the cell, only quarter of one unit cell is treated in this analysis. The boundary condition formulation is identical to that in Llorca et al. ${ }^{(17)}$ and Christman et al. ${ }^{(18)}$. The boundary conditions are as follows:

$\mathrm{u}_{\mathrm{z}}=0, \quad \tau_{z y}=\tau_{z x}=0 \quad$ on $\mathrm{z}=0$

$\mathrm{u}_{\mathrm{x}}=0, \quad \tau_{x z}=\tau_{x y}=0 \quad$ on $\mathrm{x}=0$

$\mathrm{u}_{\mathrm{y}}=0, \quad \tau_{y z}=\tau_{x y}=0 \quad$ on $\mathrm{y}=0$

$\mathrm{u}_{\mathrm{z}}=\varepsilon_{\text {ave }} \mathrm{L} / 2, \quad \int_{x=0}^{x=H / 2} \int_{y=0}^{y=H / 2} \tau_{x z} d x d y=0, \iint \tau_{z y} d x d y=0$ on $\mathrm{z}=\mathrm{L} / 2$

$\mathrm{u}_{\mathrm{y}}=\mathrm{U}_{\mathrm{y}}, \quad \tau_{y z}=\tau_{x y}=0, \int_{z=0}^{z=L / 2} \int_{x=0}^{x=H / 2} \tau_{y x} d x d z=0, \iint \tau_{y z} d x d z=0 \quad$ on $\quad \mathrm{y}=\mathrm{H} / 2$

$\mathrm{u}_{\mathrm{x}}=\mathrm{U}_{\mathrm{x}}, \quad \tau_{x z}=\tau_{x y}=0, \int_{z=0}^{z=L / 2} \int_{y=0}^{y=H / 2} \tau_{x z} d y d z=0, \iint \tau_{x y} d y d z=0 \quad$ on $\quad \mathrm{x}=\mathrm{H} / 2$

Where $\varepsilon_{\text {ave }}$ is the macroscopic strain, $\mathrm{U}_{\mathrm{y}}$ and $\mathrm{U}_{\mathrm{x}}$ are constant which are determined such that the shear component of traction is free.

\section{Numerical results and discussion}

Stress distribution along $\mathrm{z}$ direction for longitudinal loading $\left(\alpha=0^{\circ}\right.$, parallel to the 
whisker direction) is shown in Fig.9. From this figure it can be seen that the high stress is developed in the whisker compared with the stress in the matrix. From the experimental results we found that with respect to the loading direction all parallel oriented whiskers are broken. Transverse loading ( $\alpha=90^{\circ}$, perpendicular to the whisker direction) result shows (Fig.10) that the high stress is developed at the edge of interface between whisker and matrix. In the experimental results we find that with respect to the loading direction all perpendicular oriented whiskers are debonded.
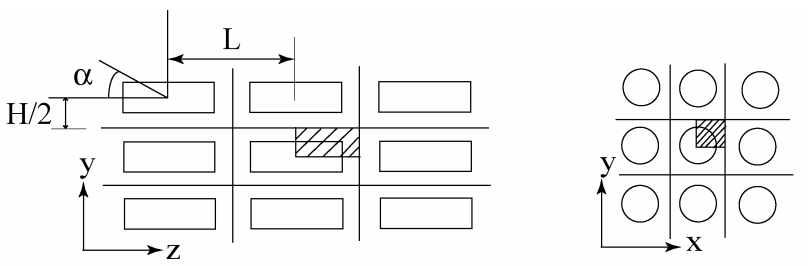

(a)

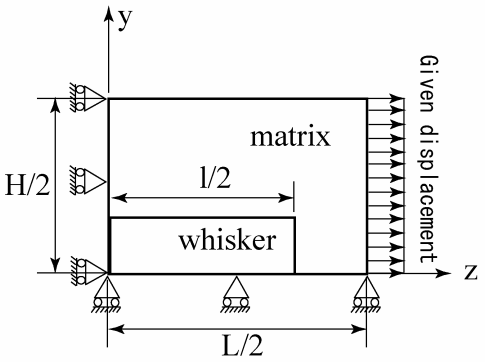

(b)

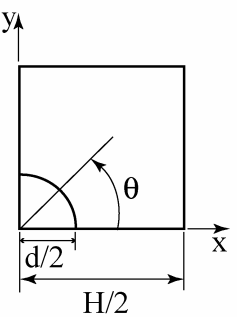

$\mathrm{H} / 2$

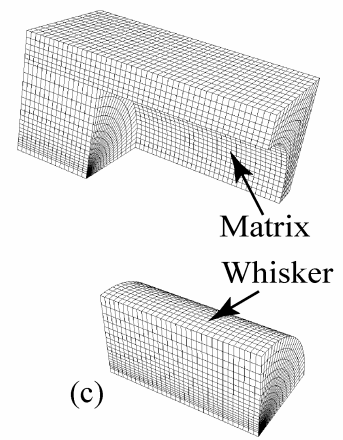

Fig.8 3-D single whisker model representing the whisker reinforced Al alloy (a) and (b) schematic illustration of the fiber arrangement (c) finite-element mesh.

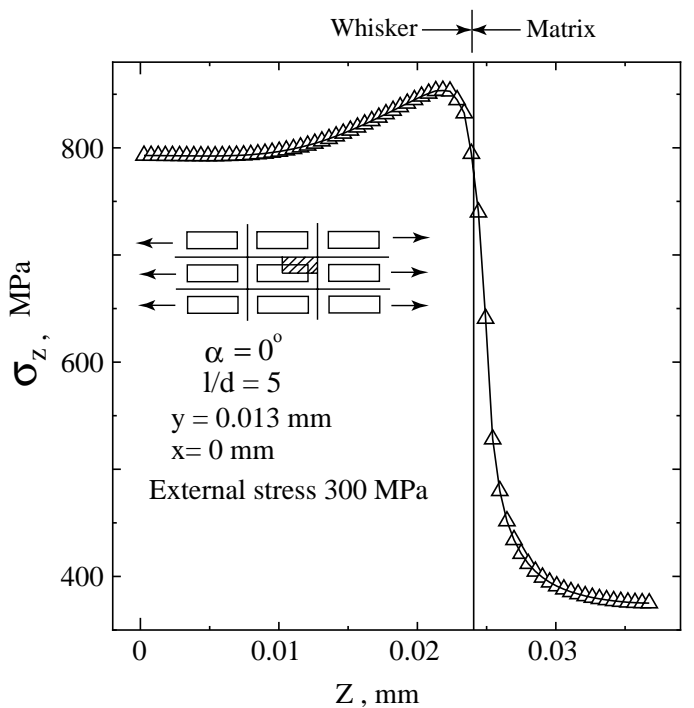

Fig.9 Stress distribution along $\mathrm{z}$ direction for longitudinal loading (parallel to the stress direction).

In our previous work ${ }^{(15)}$, a two dimensional circular inclusion array model has been conducted using finite element method to estimate the effect of macroscopic boundary between MMC and $\mathrm{Al}$ alloy on the stress distributions. The result shows that under low nominal bending stress, (156 MPa, which is one of the maximum stresses of fatigue test) the 
stress concentration around the macroscopic boundary of locally reinforced material is less than $10 \mathrm{MPa}$. A large difference in fatigue life between the locally reinforced material $\left(\alpha=90^{\circ}\right)$ and homogeneous $\mathrm{MMC}\left(\alpha=0^{\circ} \sim 90^{\circ}\right)$ can be seen experimentally (shown in Fig. 4). Thus, it can be concluded that this large difference in fatigue life is occurred due to only whisker orientation effects.

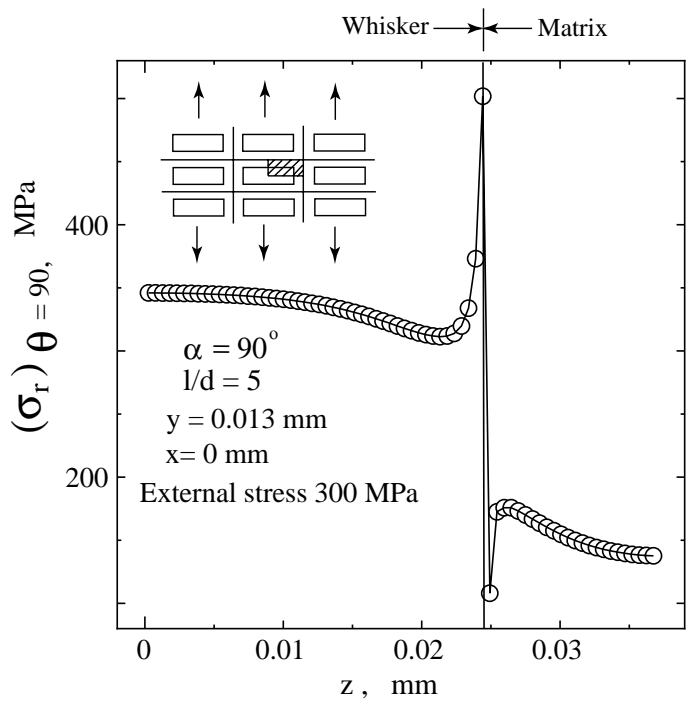

Fig.10 Stress distribution along $\mathrm{z}$ direction for transverse loading (perpendicular to the stress direction).

\section{Conclusions}

The effect of whisker orientation on monotonic and fatigue strength of an aluminium cast alloy locally reinforced by $\mathrm{SiC}$ particles and $\mathrm{Al}_{2} \mathrm{O}_{3}$ whiskers were investigated experimentally and numerically. The key findings are as follows:

1. The fatigue and monotonic strength is lower when the hybrid MMC is subjected to the stress perpendicular to the whisker orientation than those when the stress is in the random plane of the whisker orientation.

2. From the fractographic observation when the whisker direction is random $\left(\alpha=0^{\circ} \sim 90^{\circ}\right)$ to the stress direction almost all whiskers are broken. When the whisker direction is perpendicular to the stress direction almost all whiskers are debonded. This is one of the reasons why the monotonic strength and fatigue strength of the hybrid MMC is higher when the stress is in the random plane of the whisker orientation.

3. High stress takes place in the interface between whisker and matrix when the whisker orientation is normal to the loading direction $\left(\alpha=90^{\circ}\right)$ which results in interfacial debonding and causes low overall strength of the material. The maximum stress site is in the whisker when the whisker orientation is parallel to the loading direction $\left(\alpha=0^{\circ} \sim 90^{\circ}\right)$ which results in broken whiskers and causes high overall strength of the material.

\section{Acknowledgements}

We thank the Ministry of Education, Science, Sport and Culture, Government of Japan for providing financial support during this research work. 


\section{References}

(1) Suresh, S., Mortensen, A. and Needleman, A. Fundamentals of metal matrix composites. London: Butterworth/Heinemann; 1993.

(2) Zeuner, T., Stojanov, P., Sahm, P.R., Ruppert. H., and Engels A., Developing trends in disc brake technology for rail application, Material Science and Technology, Vol. 14 (1998), pp. 857-863.

(3) Levin, M. and Karlsson, B., Influence of $\mathrm{SiC}$ particle distribution and prestraining on fatigue crack growth rates in aluminium AA 6061-SiC composite, Material Science and Technology, Vol. 7 (1991), pp. 596-607.

(4) Davidson, D.L., Fatigue and fracture toughness of aluminium alloys reinforced with $\mathrm{SiC}$ and alumina particles, Composite, Vol. 24, No. 3 (1993), pp. 248-255

(5) Chen, A.L., Arai, Y. and Tsuchida, E., A Numerical Study on the Effect of Thermal Cycling on Monotonic Response of Cast Aluminium Alloy-SiC Particulate Composites, Theoretical Applied Mechanics, Vol. 53 (2004), pp. 63-73.

(6) Chen, A.L., Arai, Y. and Tsuchida, E., An experimental study on effect of thermal cycling on monotonic and cyclic response of cast aluminium alloy-SiC particulate composites, Composites: part B, Vol. 36 (2005), pp. 319-330.

(7) Srivatsan, T. S. and Al-Hajiri, M., The fatigue and final fracture behavior of SiC particle reinforced 7034 aluminium matrix composites, Composite: Part B, Vol. 33 (2002), pp. 391-404.

(8) Zhang, Q., Zhang, H., Mingyuan, G. and Yanping, J., Studies on the fracture and flexture strength of $\mathrm{Al} / \mathrm{SiC}_{\mathrm{p}}$ composite, Material letter, Vol. 58 (2004), pp. 3545-3550.1

(9) Kang, G. Z., Yang, C. and Zhang, J., Tensile properties of randomly oriented short $\delta-\mathrm{Al}_{2} \mathrm{O}_{3}$ fiber reinforced aluminium alloy composites: 1 . Microstructure characteristics, fracture mechanisms and strength prediction, Composites: part A, Vol. 33 (2002), pp. 647-656.

(10) Kang, G. Z. and Gao, Q., Tensile properties of randomly oriented short $\delta-\mathrm{Al}_{2} \mathrm{O}_{3}$ fiber reinforced aluminium alloy composites: 2 . Finite element analysis for stress transfer, elastic modulus and stress-strain curve, Composites: part A, Vol. 33 (2002), pp. 657-667.

(11) Jiang, B., Liu, C., Zhang, C., Wang, B. and Wang, Z., The effect of non-symmetric distribution of fiber orientation and aspect ratio on elastic properties of composites, Composites: part B, Vol. 38 (2007), pp. 24-34.

(12) Li, A.B., Geng, L., Meng, Q.Y. and Zhang, J., Simulation of the large compressive deformation of the metal matrix composites with misaligned whiskers, Material Science. and Engineering A, Vol. 358 (2003), pp. 324-333.

(13) Trojanova, Z., Szaraz, Z., Labar, J. and Lukac, P., Deformation behaviour of an AS21 alloy reinforced by short Saffil fibers and SiC particles, Journal of Material Processing Technology, Vol. 162-163 (2005), pp. 131-138.

(14) Liu, X. and Bathias, C., Defects in squeeze-cast $\mathrm{Al}_{2} \mathrm{O}_{3} / \mathrm{Al}$ alloy composites and their effects on mechanical properties, Composite Science and Technology, Vol. 46(1993), pp. 245-252.

(15) Rafiquzzaman, MD. and Arai, Y., Fracture mechanism of aluminium cast alloy locally reinforced by $\mathrm{SiC}$ particles and $\mathrm{Al}_{2} \mathrm{O}_{3}$ whiskers under monotonic and cyclic load, Material Science and Technology, 2007(to be published).

(16) JIS H 5202. Aluminium alloy castings, Japan Industrial Standard 2002.

(17) Llorca, L., Needleman, A. and Suresh, S., An analysis of the effects of matrix void growth on deformation and ductility in metal-ceramic composites, Acta Metallurgica et Materialia, Vol. 39, No. 10 (1991), pp. 2317-2335.

(18) Christman, T., Needleman, A. and Suresh, S., An experimental and numerical study of deformation in metal-ceramic composites, Acta Metallurgica, Vol. 37, No. 11 (1989), pp. 3029-3050 